\title{
Dependence of Knowledge Management on Organizational Characteristics
}

\author{
Quang Linh Huynh ${ }^{1, *}$, Nguyen Van Nguyen ${ }^{2}$ \\ ${ }^{1}$ School of Economics and Law, Tra Vinh University, Vietnam \\ ${ }^{2}$ Resource Development Institute, Tra Vinh University, Vietnam
}

Copyright $\bigcirc 2017$ by authors, all rights reserved. Authors agree that this article remains permanently open access under the terms of the Creative Commons Attribution License 4.0 International License

\begin{abstract}
Organizational structure and organizational culture are factors forming organizational characteristics, which are determinants of knowledge management. Prior research has explored the influence of organizational structure and organizational culture on the management of knowledge; however none of them have evaluated the relative importance of organizational culture and structure to the management of knowledge. The current project attempts to re-investigate the relations of the knowledge management with organizational structure and culture by using the multiple linear regressions. Especially, it applies the analytic hierarchy procedure to rank the comparative significance between organizational structure and organizational culture to the knowledge management. The data for analyses was obtained from 101 publicly listed firms in Vietnamese Stock Exchanges. The findings provide statistically significant evidence on the influences of organizational culture and structure on the knowledge management and the influential levels are different. This research makes some contributions. For theoretical aspect, the findings offer new evidence on the relative importance between organizational structure and organizational culture to the knowledge management that is organizational culture more important than organizational structure in boosting the implementation of knowledge management in business. On practical aspect, the empirical findings will help executives come to better decisions in the management of knowledge conditional on kinds of organizational characteristics.
\end{abstract}

Keywords Knowledge Management, Organizational Characteristics, Comparative Impact

\section{Introduction}

The management of knowledge is mentioned as a multidisciplinary tool to obtain successes of an organization wisely using their knowledge. It is recognized as the process of acquiring, organizing, using, sustaining, sharing and renovating workers' knowledge so that they can improve organizational efficiency [1]. Besides, the management of knowledge in business is recommended by Chen and Huang [2] as a critical factor in supporting and improving organizational efficiency. In the same year, Lakshman [3] regards knowledge management as an organizational competence guiding their staff to do tasks together to generate, share, and leverage their collective knowledge to augment their competitive advantages. The previous studies [4; 5] define the management of knowledge as the extent to which organizations are satisfied with their management level of knowledge resulting in differently sharing and adopting knowledge.

According to Huynh and Soon [6], the knowledge management in a firm is conditional on various factors, such as organizational culture and organizational structure. Additionally, Miles et al. [7] identified organization as a group together working to attain their joint objective. The group has to efficiently arrange the tasks to work together proficiently for their organizational objectives. Organizations can be structured in many different ways, conditional on their goals. Every firm has their own structure simplifying the responsibilities of members in performing work, in order that they can exactly know their duties in their firm. The structure of organization is regarded by Chen and Huang [2] as a system composed of institutional regulations and rules designed to plan how work is assigned in firms. In addition, it verifies how information runs from level to level within a firm.

Organizational structure plays a vital role in organizations, as it creates an efficient system of work and communication. Further, every organization has a unique culture to make it different from the others and give it a sense of direction. It is critical for the employees to understand the culture of their organization to adjust well. Huynh and Soon [6] refer to organizational culture as a workplace climate that is created from the communication, cooperation, and interaction among the employees in a firm. The interaction and behaviors of employees contribute to a 
unique cultural environment of an organization; while Tanase [8] indicates that, organizational culture is an important driver of organizations. It generates an operational environment that everyone seeks to attain their objective established by the firm. The criteria used to measure and assess the employees' performance are based on that environment.

The dynamic view proposes that organizational culture help a firm cope with its business environment. Previous research projects have investigated and suggested both organizational structure and organizational culture as a determinant leading to the management of knowledge $[2 ; 6$; $9 ; 10 ; 11]$; and some of them have explored the impacts of both organizational structure and culture on the management of knowledge in the joint research model. However, no study has examined the comparative importance of organizational structure compared with organizational culture to the knowledge management. Based on the previous underpinning on the association among organizational structure, culture and the management of knowledge, in which, knowledge management is driven by organizational structure and organizational culture. This research seeks to evaluate the impact of organizational structure and organizational culture on the management of knowledge in business. It particularly compares the relative importance to which the variables of organizational culture and structure contribute to the knowledge management in business.

In order for evaluating the comparative significance between organizational culture and structure to the the management of knowledge, the current project is the first to utilize the analytic hierarchy procedure to make pair-wise comparisons between all the judgments with each other. The empirical findings reveal that, both organizational structure and organizational culture statistically impact the knowledge management in business, consistent with the previous research. Furthermore, this research provides evidence on the relative importance between organizational structure and organizational culture to the knowledge management in that organizational culture more strongly impacts the knowledge management in business than organizational structure does. The rest of the current research project keeps on as follows. The next part reviews relevant literature, which develops the research hypotheses. The method is presented in Part 3, which describes the guidance for collecting and analyzing the data. Part 4 offers practical findings. Concluding part discusses the findings and highlights some implications.

\section{Literature Review}

The literature review explore how accepted organizational structure affects the way an organization manages their knowledge in order to achieve their best firm performance and how knowledge management is related to organizational culture. The literature in organizational structure, culture and knowledge management will be reviewed below.

Drawing on Lin and Lee [4] and Gold et al. [5], Huynh and Soon [6] indicate that knowledge management is evident in an organization when any of the five items below exists: (1) the sharing of knowledge between subordinates and supervisors, (2) the sharing of knowledge among employees, (3) The sharing of knowledge across the departments, (4) efficient management of various types of knowledge sources, and (5) practical adoption of knowledge. In addition, Rogers [12] and Chen and Huang [2] regard organizational structure as a variable of: (1) decentralization, (2) mutual adjustment and (3) integration. Chen and Huang [2] discover that the structure of organization is positively associated with the sharing and adoption of knowledge. Yap et al. [9] argue that when knowledge is applied, the structure of organization should always be taken into account. Thus, organizational structure is considered to affect the management of knowledge. In addition, the findings of Enayati and Ghasabeh [11] reveal that the structure of organization is very essential to the effectiveness of knowledge management implementation; whereas, Huynh and Soon [6] provide statistical evidence on the influence of organizational structure on the management of knowledge in business. The above mentioned arguments help hypothesize the hypothesis $\mathrm{H} 1$ "organizational structure makes an important contribution to the knowledge management in business".

Furthermore, Marshall [13] describes organizational culture as values, norms, and behaviors, which characterize an organization and its working environment. That scholar also refers to the attributes of organizational culture as innovative and cooperative working environments, trust, communication, and coordination among members, as well as accessibility of leadership and power relationships. It is indicated in previous studies that organizational culture affects the knowledge management, in which it brings success to organizations that implement knowledge management [14]. Organizational culture refers to innovative cooperative climate (Jaw and Liu 2003 [15]), trust, communication, and coordination among employees [16]. Moreover, Chen's and Huang's research on "how organizational climate and structure affect knowledge management" [2] uncovers that organizational interaction considered as organizational culture positively impacts on the sharing as well as adoption of knowledge. According to Yap et al. [9], the culture of organization should be carefully considered when knowledge management is applied to business. Organizational culture is proposed by Enayati and Ghasabeh [11] to play a vital role in the knowledge management. Besides, Magnier-Watanabe et al. [17] recommend that the activities of knowledge management need to be tailored to the culture of organization, while Erwee et al. [10] find out that 
organizational culture affects both knowledge management strategies and process. Following them, Huynh and Soon [6] explore the complicated link among structure, culture and knowledge management and offer statistical support for the link between the culture of organization and the management of knowledge. Based on the preceding discussions, it theorizes the hypothesis $\mathrm{H} 2$ "organizational culture makes a vital contribution to knowledge management in business".

\section{Method}

Multiple linear regressions: To check the research hypotheses on the influences of organizational structure and organizational culture on the knowledge management in business, this research project performed multiple linear regressions with the following steps.

a. Scales: Knowledge management $(\mathrm{KM})$ is composed of the five items, namely (1) the sharing of knowledge between supervisors and subordinates: KM1, (2) the sharing of knowledge among employees: KM2, (3) the sharing of knowledge across the departments: KM3, (4) efficient management of various types of knowledge sources: KM4, and (5) practical adoption of knowledge: KM5, adapted from Gold et al. [5], Huynh and Soon [6] and Lin and Lee [4]. A five-point scale (highly dissatisfied, dissatisfied, a little satisfied, fairly satisfied and highly satisfied) is used to evaluate these five dimensions. Organizational structure (OS) is formed from three states, namely (1) decentralization: OS1, (2) mutual adjustment: OS2, and (3) integration: OS3. A five-point scale is used to assess the three items of organizational structures. The measurements are based on Rogers [12], Chen and Huang [2] and Huynh and Soon [6]. Organizational culture (OC) consists of innovative climate (OC1), cooperative climate (OC2), trust (OC3), communication (OC4), and coordination (OC5). The five items are evaluated using a five-point scale, adapted from Sivadas and Dwyer [16] and Huynh and Soon [6].

b. Statistical analyses: Before the research hypotheses are tested, we applied a reliability analysis to check the properties of constructs and the dimensions forming them. The analysis of reliability is utilized to evaluate the extent the items of the same constructs agree with each other [18]. It provides information on the links between individual dimensions in the construct. If the link is well-built, the construct will generate dependable results and is therefore consistent. Then we employ multiple linear regressions to assess the influences of organizational culture and structure on the management of knowledge in business.

Analytic hierarchy process: To evaluate the comparative importance between organizational culture and structure to the management of knowledge in business, we employ the analytic hierarchy procedure that is an instrument for multi-criteria judgment as well as for the analyses of the decision-making process, which is introduced by Saaty [19]. This procedure has the subjective evaluation of each evaluation-maker as input and the quantitative weight of each option as output. The procedure is considered as a compensatory technique that decomposes a complex judgment problem into a hierarchy. Pair-wise comparisons between all choices with each other are applied to acquire the eigenvectors and scores. The judgment scale for pair-wise comparisons is applied. If attribute $\mathrm{A}$ is as equally significant in contributing to their factor as attribute $\mathrm{B}$, it is rated at 1 . If attribute $\mathrm{A}$ is absolutely more significant in contributing to their factor than attribute $\mathrm{B}$, it is rated at 5 . If attribute $\mathrm{B}$ is absolutely less significant in contributing to their factor than attribute A, it is valued at $1 / 5$. It is similar for "more significant- 3 " or "intermediate values- 2 and 4". There are three steps to carry out the procedure.

a. Framework stratification: A factor is decomposed into its elements. Arranging all the components in a hierarchy recommend an overall view of the intricate links and helps to assess whether elements in each level have the same magnitude in order that they can be exactly judged. A component in a given level serves as an attribute for comparison. A hierarchy in this research includes two levels. Level 1 consists of 'Organizational structure' and 'Organizational culture'. Level 2 is composed of decentralization, mutual adjustment and integration (3 elements) on 'Organizational structure'; and cooperative climate, innovative climate, communication, trust and coordination (5 elements) on 'Organizational culture'.

b. Pair comparison: For each pair, decision-makers are asked to assess how significant element $\mathrm{A}$ is compared to element B. Each of these judgments is assigned a number from 1 to 5. Firstly, 'Organizational structure' and 'Organizational culture' are compared with each other. Then three elements of organizational structure are compared with one another. Simultaneously five elements of organizational culture are also compared with one another. Finally, the matrices of the judgments are established. Those matrices decide the eigenvectors of the elements within each level, called the local eigenvectors.

Data collection: The economy in Asia grows fastest in the world, including Vietnam. Vietnam is chosen for analyses in the current study, since it is one of the fastest growing markets in the Southeast Asia. The sample for this study is a total population of 1130 companies publicly listed on Vietnamese Stock Exchanges. There are 13 measured variables in this research, so a sample of 65 observations $(=13 * 5)$, stipulated by Hair et al. [20], is needed. For a sufficient sample of usable responses, a survey of 130 publicly listed firms is conducted (an increase by $100 \%$ compared to the required sample size of 65). For each firm, we get in touch with a manager involved in knowledge management to fill a questionnaire. Of the 130 questionnaires that were handed out, there are only 101 which offered positive outcomes with useful 
answers. Finally, we acquired 101 useful replies with sufficiently required information for analyses.

\section{Practical Finding}

\subsection{Test of the Research Hypotheses}

The findings from the reliability analyses (untabulated) are utilized to check the scale reliability of the data. The results show that thirteen items, which make up the three variables, achieve their item-total correlations of over 0.5 , the smallest limit recommended by Nunnally [18]. Additionally, all the Cronbach alphas surpass 0.7 as the recommended level by Nunnally [18]. These findings show that the constructs satisfy the internal reliability. Therefore, it can be ensured that our data has the adequately reliable constructs. Before further analyses, the composite variables are computed by taking an average of their own dimensions (OS1, OS2 and OS3 for OS; OC1, OC2, OC3, OC4 and OC5 for OC; KM1, KM2, KM3, KM4 and KM5 for $\mathrm{KM}$ ). The composite variables $\mathrm{OS}, \mathrm{OC}$ and $\mathrm{KM}$ are entered into the linear regressions. The findings are illustrated in Table 1, indicating that $33.4 \%$ of total variation in the management of knowledge is explained by organizational culture and structure. The research model achieves the value of $\mathrm{F}$ of 24.619 at the $1 \%$ significance level; suggesting that our research model is statistically significant and gets a good fit to the data.

Moreover, the figures from Table 1 also provide statistical support for the hypotheses $\mathrm{H} 1$ and $\mathrm{H} 2$ at the $1 \%$ significance level (with significances of 0.005 for organizational structure and 0.000 for organizational culture). The influence of organizational structure on the management of knowledge in business is positive with the coefficient of 0.218 ; while the effect of organizational culture on the knowledge management in business is also positive but with the coefficient of 0.370 , which implies that organizational culture can put a stronger effect on the management of knowledge than organizational structure does. The relative effect between organizational structure and culture on the management of knowledge is not apparent with the regression analysis, therefore in order to comprehensively investigate the relative importance of organizational structure and culture on the management of knowledge, we employ the analytic hierarchy procedure.

Table 1. Regression analysis

\begin{tabular}{|c|c|c|c|c|c|c|c|c|}
\hline Explained Variable & Explanatory Variable & Coefficients & Std. Error & t-statistics & $\operatorname{Sig}_{\cdot t}$ & $\mathrm{R}^{2}$ & $\mathrm{~F}$ & $\operatorname{Sig}_{\cdot F}$ \\
\hline \multirow{3}{*}{ KM } & Constant & 1.685 & 0.277 & 6.085 & 0.000 & \multirow{3}{*}{0.334} & \multirow{3}{*}{24.619} & \multirow{3}{*}{0.000} \\
\hline & OS & 0.218 & 0.075 & 2.895 & 0.005 & & & \\
\hline & $\mathrm{OC}$ & 0.370 & 0.077 & 4.814 & 0.000 & & & \\
\hline
\end{tabular}

\subsection{The relative Importance of Elements}

Table 2. Local eigenvector for Knowledge management

\begin{tabular}{|c|c|c|c|c|c|c|}
\hline & OC & OS & The $2^{\text {nd }}$ root of values & Eigenvector & New Vector & New Vector/Eigenvector \\
\hline OC & 1.00 & 3.13 & 1.77 & 0.76 & 1.52 & 2.00 \\
\hline OS & 0.32 & 1.00 & 0.57 & 0.24 & 0.48 & 2.00 \\
\hline Total & & & 2.34 & 1.00 & & 4.00 \\
\hline
\end{tabular}

where:

Eigenvector: $w_{j}=$ the $2^{\text {nd }}$ root of value $j_{j}$ the total of the $2^{\text {nd }}$ root of values

New vector: $\left[v_{l j}\right]=\left[a_{j j}\right] \times\left[b_{l j}\right]$

$\left[a_{j j}\right]$ is the matrix of the 2 components with 2 columns and 2 rows

$\left[b_{1 j}\right]$ is the matrix of the Eigenvectors with 1 column and 2 rows

$\lambda_{\max }=\operatorname{Sum}($ New Vector/Eigenvector $) / 2=4.00 / 2=2.00$

$C I=\left(\lambda_{\max }-n\right) /(n-1)=(2.00-2) /(2-1)=0.00$, so $C R=C I / R I_{n}=0.00$

With the sample of 101 firms, taking an average for each component and employing the Saaty [19] method, we gain component eigenvectors of each level as given in Tables 2, 3 and 4. The results from Table 2 shows that organizational culture is slightly over three time more important in explaining the knowledge management than organizational structure is (0.76 compared to 0.24). It is calculated from Table $2, \mathrm{CI}$ is 0.00 and $\mathrm{CR}$ is also 0.00 far less than 0.1 , the accepted limit proposed by Saaty [19]. The consistency test of the eigenvectors is satisfied; as a result those eigenvectors be able to be used for further analyses.

Table 3 demonstrates the relative importance between components to organizational structure; whereas Table 4 describes the relative importance between components to organizational culture. Table 3 demonstrate that the research model achieves CI of 0.00 and CR of 0.00 that are far smaller than 0.1, the proposed limit by Saaty [19]. The consistency 
test of this analysis is entirely met. Consequently those eigenvectors are suitable for following analyses. The numbers from Table 4 indicate that CI obtains the value of 0.008 ; while CR gets the value of 0.007 ; which imply that the analysis is reliable for use in the following steps.

Table 3. Local eigenvector for Organizational structure

\begin{tabular}{|c|c|c|c|c|c|c|c|}
\hline & OS1 & OS2 & OS3 & The $3^{\text {rd }}$ root of values & Eigenvector & New Vector & New Vector/ Eigenvector \\
\hline OS1 & 1.00 & 1.91 & 1.99 & 1.56 & 0.49 & 1.48 & 3.02 \\
\hline OS2 & 0.52 & 1.00 & 1.14 & 0.84 & 0.26 & 0.77 & 2.96 \\
\hline OS3 & 0.50 & 0.88 & 1.00 & 0.79 & 0.25 & 0.75 & 3.00 \\
\hline Total & & & & 3.19 & 1.00 & & 8.98 \\
\hline
\end{tabular}

where:

Eigenvector: $w_{j}=$ th $3^{\text {rd }}$ root of value v $_{j}$ the total of the $3^{\text {rd }}$ root of values

New vector: $\left[v_{1 j}\right]=\left[a_{i j}\right] x\left[b_{1 j}\right]$

$\left[a_{i j}\right]$ is the matrix of the 3 components with 3 columns and 3 rows

$\left[b_{1 j}\right]$ is the matrix of the Eigenvectors with 1 column and 3 rows

$\lambda_{\max }=\operatorname{Sum}($ New Vector/Eigenvector $) / 3=8.98 / 3=3.00$

$C I=\left(\lambda_{\max }-n\right) /(n-1)=(3.00-3) /(3-1)=0.00$

With ' $n$ '=3, $R I_{n}$ is 0.58; hence, $C R=C I / R I_{n}=0.00$

The results derived from the local and global eigenvector calculation is offered in Table 5. The findings show that the local rank of the two constructs "organizational structure" and "organizational culture", in that organizational culture is ranked stronger than organizational structure in affecting the knowledge management. Table 5 also displays the local and overall ranks of the "organizational culture" and "organizational structure".

Table 4. Local eigenvector for Organizational culture

\begin{tabular}{|c|c|c|c|c|c|c|c|c|c|}
\hline & OC1 & OC2 & OC3 & OC4 & OC5 & The $5^{\text {th }}$ root of values & Eigenvector & New Vector & New Vector/ Eigenvector \\
\hline OC1 & 1.00 & 1.07 & 2.13 & 2.25 & 3.67 & 1.80 & 0.32 & 1.60 & 5.00 \\
\hline OC2 & 0.94 & 1.00 & 2.04 & 2.07 & 2.93 & 1.59 & 0.29 & 1.46 & 5.03 \\
\hline OC3 & 0.47 & 0.49 & 1.00 & 1.14 & 2.12 & 0.86 & 0.15 & 0.79 & 5.27 \\
\hline OC4 & 0.44 & 0.48 & 0.88 & 1.00 & 2.02 & 0.82 & 0.15 & 0.73 & 4.87 \\
\hline OC5 & 0.27 & 0.34 & 0.47 & 0.50 & 1.00 & 0.48 & 0.09 & 0.45 & 5.00 \\
\hline Total & & & & & & 5.55 & 1.00 & & 25.17 \\
\hline
\end{tabular}

where:

Eigenvector: $w_{j}=$ the $5^{\text {th }}$ root of value $/$ the total of the $5^{\text {th }}$ root of values

New vector: $\left[v_{1 j}\right]=\left[a_{j j}\right] \times\left[b_{1 j}\right]$

$\left[a_{j j}\right]$ is the matrix of the 5 components with 5 columns and 5 rows

$\left[b_{1 j}\right]$ is the matrix of the eigenvectors with 1 column and 5 rows

$\lambda_{\max }=\operatorname{Sum}($ New Vector/Eigenvector $) / 5=25.17 / 5=5.034$

$C I=\left(\lambda_{\max }-n\right) /(n-1)=(5.034-5) /(5-1)=0.008$

With ' $n$ '=5, $R I_{n}$ is 1.12; hence, $C R=C I / R I_{n}=0.007$

For organizational culture, innovative climate $(\mathrm{OC} 1)$ is ranked the first and cooperative climate $(\mathrm{OC} 2)$ comes the second; whereas trust (OC3) and communication (OC4) both take the third position. And finally, coordination (OC5) stands at the weakest position. In regard with organizational structure, decentralization (OS1) takes the first, followed by mutual adjustment (OS2), and finally integration (OS3) comes to the last. For the relative importance of components to the knowledge management, innovative climate (OC1) and cooperative climate $(\mathrm{OC} 2)$ are graded as the first and second; while decentralization (OS1) arrives at the third. Trust (OC3) and communication (OC4) take the same position of the fourth next to the fifth of coordination (OC5). Mutual adjustment (OS2) and integration (OS3) both take the sixth position or the last. 
Table 5. Local and global eigenvectors and ranks

\begin{tabular}{|c|c|c|c|c|c|c|c|}
\hline Factors & $\begin{array}{c}\text { Local } \\
\text { Eigenvectors } \\
\end{array}$ & $\begin{array}{l}\text { Local } \\
\text { Rank }\end{array}$ & Components & $\begin{array}{c}\text { Local } \\
\text { Eigenvectors }\end{array}$ & $\begin{array}{l}\text { Local } \\
\text { Rank }\end{array}$ & $\begin{array}{c}\text { Global } \\
\text { Eigenvectors }\end{array}$ & $\begin{array}{c}\text { Overall } \\
\text { Rank }\end{array}$ \\
\hline \multirow{5}{*}{$\begin{array}{l}\text { Organizational } \\
\text { culture }\end{array}$} & \multirow{5}{*}{0.76} & \multirow{5}{*}{1} & $\mathrm{OC} 1$ & 0.32 & 1 & 0.25 & 1 \\
\hline & & & $\mathrm{OC} 2$ & 0.29 & 2 & 0.22 & 2 \\
\hline & & & OC3 & 0.15 & 3 & 0.11 & 4 \\
\hline & & & $\mathrm{OC} 4$ & 0.15 & 3 & 0.11 & 4 \\
\hline & & & OC5 & 0.09 & 4 & 0.07 & 5 \\
\hline \multirow{3}{*}{$\begin{array}{l}\text { Organizational } \\
\text { structure }\end{array}$} & \multirow{3}{*}{0.24} & \multirow{3}{*}{2} & OS1 & 0.49 & 1 & 0.12 & 3 \\
\hline & & & OS2 & 0.26 & 2 & 0.06 & 6 \\
\hline & & & OS3 & 0.25 & 3 & 0.06 & 6 \\
\hline
\end{tabular}

\section{Implication and Conclusion}

This research provides management researchers with an insight into the relative importance between organizational structure and organizational culture on the knowledge management in business in which overall organizational culture is more important than organizational structure in leading to the implementation of knowledge management in business. For specific elements, decentralization of organizational structure is the third most important element to the knowledge management in business just behind innovative climate and cooperative climate of organizational culture. The findings are is also helpful to executive managers by offering them with better understand of the comparative effects between organizational culture and structure on the management of knowledge in business. Thus, they can better decide on implementing the management of knowledge in business, which will result in the best possible organizational performance.

The objective of the current project is to investigate the impacts of organizational structure and organizational culture on the management of knowledge in business; especially evaluate the comparative importance of those two factors to the knowledge management in business that has ignored in prior knowledge of management. To rank the comparative contributions between organizational structure and organizational culture to the knowledge management, this research employs the analytic hierarchy procedure to make pair-wise comparisons between all the judgments with one other. The findings offer statistical evidence on the influences of organizational culture and structure on the knowledge management in business, consistent with the previous research. Importantly, this study evidences that the importance between organizational culture and structure to the knowledge management is different in which organizational culture is more vigorous in affecting the knowledge management in business than organizational structure.

It is acknowledged that there are some limitations in this research. Our data was based on single informants from organizations; so bias problem can exist. Future studies could employ a multi-informant research design to minimize the bias problem. We conducted this research in Vietnam as a developing country, however the results are expected for other economies; but business conditions among different economies is often different, therefore one should generalize the findings from this research with care.

\section{REFERENCES}

[1] Girard J.P. and Girard J.L. Defining knowledge management: Toward an applied compendium. Online Journal of Applied Knowledge Management, 3(1), 1-20, 2015

[2] Chen C.J. and Huang J.W. How organizational climate and structure affect knowledge management: The social interaction perspective. International Journal of Information Management, 27(2), 104-118, 2007

[3] Lakshman C. Organizational Knowledge Leadership: A Grounded Theory Approach. Leadership and Organization Development Journal, 28(1), 51-75, 2007

[4] Lin H.F. and Lee G.G. Impact of organizational learning and knowledge management factors on e-business adoption. Management Decision, 43(2), 171-188, 2005

[5] Gold A.H., Malhotra A. and Segars A.H. Knowledge management: An organizational capabilities perspective. Journal of Management Information System, 18(1), 185-214, 2001

[6] Huynh Q.L., and Soon L. The Intricate Links among Culture, Structure and Knowledge Management. International Journal of Business and Management Invention, 3(4), 24-30, 2014

[7] Miles R.E., Snow C.C., Meyer A.D. and Coleman H.J. Organizational strategy, structure and process. Academy of management review, 3(3), 546-562, 1978

[8] Tanase I.A. The importance of organizational culture based on culture transfer, Proceedings of the $9^{\text {th }}$ International Management Conference "Management and Innovation For Competitive Advantage", 848-852, Bucharest, Romania, 2015

[9] Yap L.S., Tasmin R., Rusuli M.S.C. and Hashim N. Factors 
Influencing Knowledge Management Practices among Multimedia Super Corridor (MSC) organizations. Communications of the IBIMA, Article ID 834296, 2010

[10] Erwee R., Skadiang B. and Roxas B. Knowledge management culture, strategy and process in Malaysian firms. Knowledge management Research and Practice, 10(1), 89-98, 2012

[11] Enayati G. and Ghasabeh M.S. Studying the effects of organizational culture, organizational structure, and information technology on effectiveness of knowledge management: Using Khorasan Regional Electricity Company as a case study. African Journal of Business Management, 6(24), 7170-7183, 2012

[12] Rogers E.M. Diffusion of innovations, Fourth Edition Ed. New York, Free Press, USA, 1995

[13] Marshall J. Making Mergers Work: The Strategic Importance of People (Bookshelf). Financial Executive, 18(1), 14-15, 2002

[14] Alazmi M. and Zairi M. Knowledge management critical success factors. Total Quality Management \& Business
Excellence, 14(2), 199-204, 2003

[15] Jaw B.S. and Liu W. Promoting organizational learning and self-renewal in Taiwanese companies: The role of HRM. Human Resource Management, 42(3), 223-241, 2003

[16] Sivadas E. and Dwyer F.R. An Examination of Organizational Factors Influencing New Product Success in Internal and Alliance based Processes. Journal of Marketing, 64(1), 31-50, 2000

[17] Magnier-Watanabe R., Benton C. and Senoo D. A study of knowledge management enables across cultures. Knowledge management Research and Practice, 9(2), 1728,2011

[18] Nunnally J.C. Psychometric Theory. New York: McGraw-Hill, USA, 1978

[19] Saaty T.L. The Analytic Hierarchy Process. New York, McGraw-Hill, USA, 1980

[20] Hair J.F., Black W.C., Babin B.J. and Anderson R.E Multivariate Data Analysis. New Jersey: Prentice Hall, USA, 2010. 